\title{
Explainer:
}

\section{Bad housing supply assumptions}

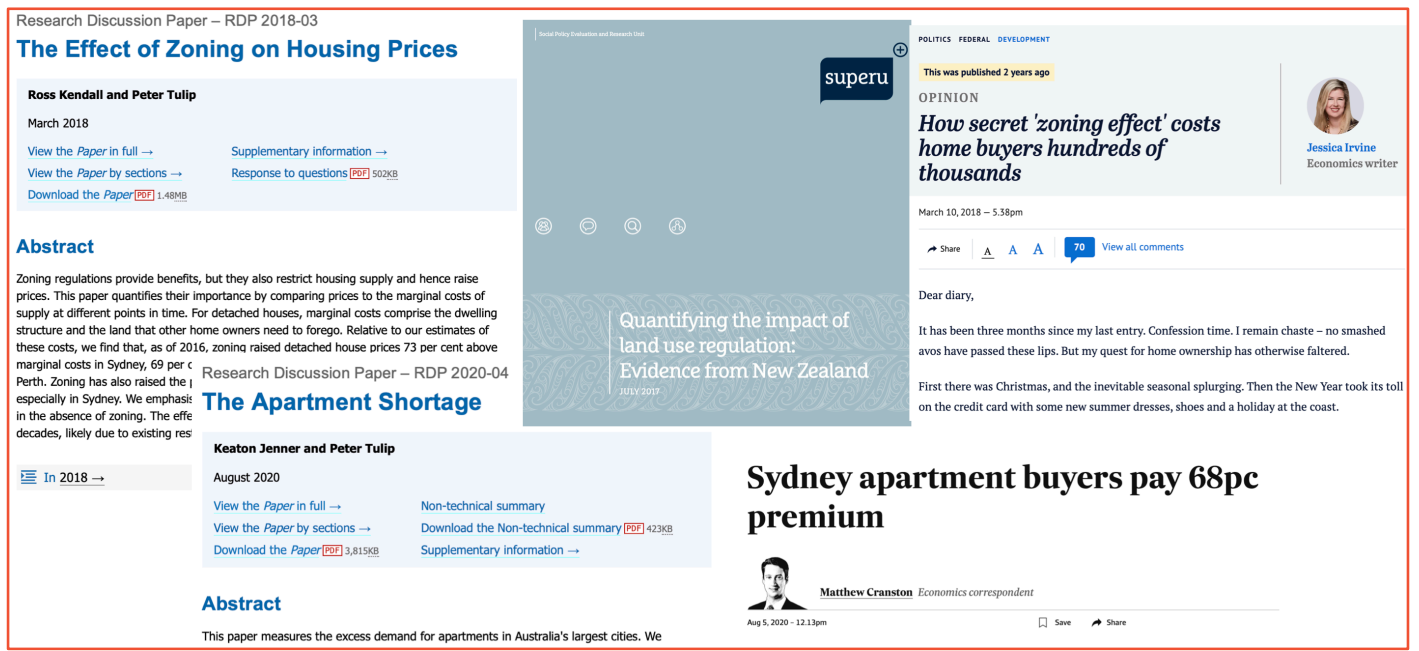

Dr Cameron K. Murray

Henry Halloran Trust, The University of Sydney

May 2021

Glaeser and Gyourko (2003) (G\&G) famously argued that if the marginal cost of a square metre of housing lot land is less than the average cost, this is evidence of a price effect from "artificial" supply constraints. They call this price gap a "regulatory tax", but it is also known as a "zoning effect" or "zoning tax".

Their logic has been relied upon by hundreds of other studies and in numerous replications of their approach, including by economists from the Reserve Bank of Australia, whose results were widely publicised (Kendall and Tulip, 2018). However, the economic assumptions behind G\&G's approach are implausible. Although popular, their method should not be relied upon to infer anything about the nature of housing supply. This note explains why.

\section{The logic}

G\&G's method is simple but subtle. They compare the marginal and average price per area of land of a vacant housing lot.

What is the marginal price? It is the extra price of buying a housing lot one square metre bigger than the average size. For example, if the average lot in a suburb is 500 square metres and sells for $\$ 500,000$, and a 501 square metre lot sells for $\$ 500,500$, the marginal

\footnotetext{
1 In practice, they use data on developed lots, not just vacant ones, and subtract construction costs of dwellings to measure these two vacant land prices.
} 
price is the extra $\$ 500 / \mathrm{sqm}$. In this case, the average price is the $\$ 1000 / \mathrm{sqm}$ that the average 500 square metre lot sells for.

In this example, the average price is $\$ 1000 / \mathrm{sqm}$ and the marginal price is $\$ 500 / \mathrm{sqm}$. By G\&G's logic, the $\$ 500 /$ sqm gap is a "regulatory tax", which equates to $\$ 250,000$ in value for the average lot. It is assumed that since marginal pieces of land can be purchased for $\$ 500 / \mathrm{sqm}$ and sold at $\$ 1000 / \mathrm{sqm}$ there is an arbitrage opportunity to assemble marginal pieces of land into new housing lots. Because land reassembly is not done until this price gap is eliminated, there must be an "artificial constraint" keeping average prices above the marginal "free market" price of land.

Two economic assumptions in this story are not valid. First is the assumption that it is zoning constraining arbitrage opportunities for assembling marginal land. Second is the assumption that the marginal price is the "free market" price of land. It is these invalid assumptions alone that determine the conclusions from this approach.

\section{Land assembly arbitrage assumption}

The problem with this assumption is that it ignores that land has both location and size attributes. Small marginal pieces of land cannot simply be assembled into new housing lots unless they are adjacent. Figure 1 is a diagram of a suburban block with ten housing lots with existing dwellings marked with dashed grey, each on a $550 \mathrm{sqm}$. If the price and sales data for this suburb was as per our previous example (average lot size of 500 sqm, average price of $\$ 1,000 / \mathrm{sqm}$ and a marginal price of $\$ 500 / \mathrm{sqm})$, what process needs to take place to remove the $\$ 250,000$ "regulatory tax"?

One option is that 50 sqm of marginal land is taken from each of the ten lots to create a new eleventh lot. A potential set of marginal pieces of land is marked in red in Figure 1. The problem is that these ten marginal pieces of land are all in different locations and cannot be assembled. They are non-contiguous. The only way to assemble these marginal pieces of land is to demolish the whole block of ten houses and redraw the lot boundaries to fit eleven lots on the block. This process is going to be uneconomical in almost all circumstances.

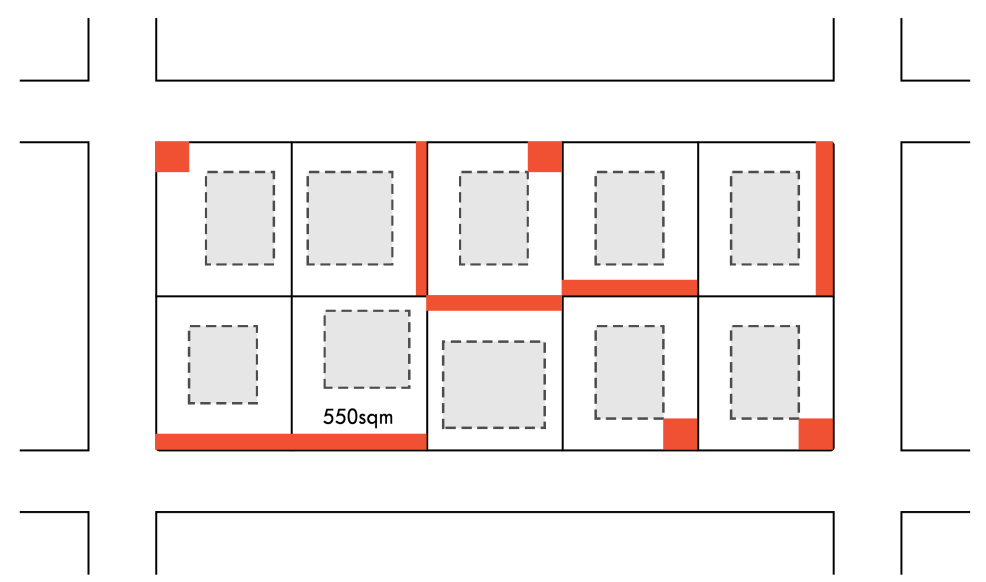

Figure 1: Marginal land is always at different locations

A more reasonable assumption is that even in the absence of zoning, economic factors are a major constraint on land reassembly. Indeed, even if this suburban block was in a new subdivision, it may be the case that not all housing lots can be subdivided exactly at the optimal land size due to geographic constraints, and G\&G's approach would show a large "regulatory tax" in this unconstrained scenario. 
This difference between the average and marginal costs of land has been observed by real estate economists for over 40 years. It is known that the difficulties of reassembling small noncontiguous pieces of land mean that marginal and average price differences will exist in an economic equilibrium. Indeed, the value of many of these small pieces of non-contiguous land should be close to zero.

\section{"Free market" land price assumption}

A related assumption concerns the interpretation of marginal and average housing lot prices. G\&G assume the marginal price is what land would be worth on average in the absence of zoning (a "free market" price). But why is the average price not the "free market" price, with the marginal price being held down by the inability to reassemble housing lots?

There are two reasonable alternative assumptions that could be made. The first is that, as real estate economists had previously shown, ${ }^{2}$ private land markets can sustain an equilibrium where the marginal price is below the average price for housing lots. Figure 2 shows an example of the shape of the total land value curve in such an equilibrium. Small lots that cannot be recombined with other lots, and small marginal pieces of land attached to larger lots, have a lower value per square metre than the average. The marginal land price is held down below the average price by physical and economic constraints on land reassembly, not zoning constraints.

Figure 1 - Land Value $(V)$ and Parcel Size $(A)$

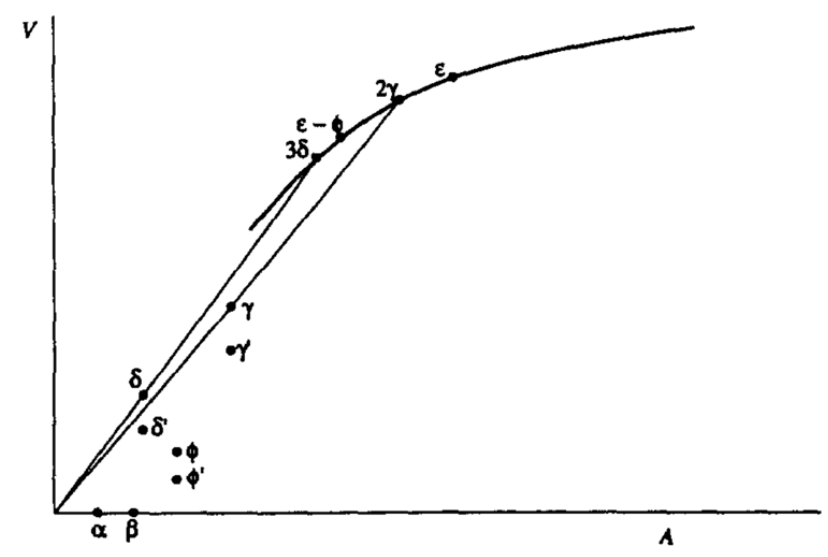

Figure 2: An expected relationship between housing lot size and price ${ }^{3}$

Another plausible alternative assumption is that the value of a housing lot comes from two components; a fixed location premium per lot paid to access the amenity around the site and a land price per square metre of a lot to access a larger space. Under this assumption, the average price will be higher than the marginal price because of a location premium, and under this alternative assumption, G\&G's approach simply estimates the location premium, not a "regulatory tax".

We now have two more plausible alternative assumptions about the economic meaning of a gap between average and marginal housing lot prices. Depending on the chosen assumption, the gap between marginal and average housing lot prices is either a "regulatory tax", a reassembly loss, or a location premium. Under the more plausible assumptions, the marginal price of land cannot be interpreted as a "free market" price from which prices have deviated.

2 See Colwell \& Sirmans (1993).

${ }^{3}$ From Colwell \& Sirmans (1993, p784). The slope of a straight line from the origin to a data point represents the average land value, while the slope of the flatter curve between nearby data points represents the marginal price. 
G\&G merely assume it is, without justification, and against all established wisdom about land and housing markets.

\section{Other peculiarities}

Some final points are relevant to this summary critique. First, G\&G's estimated "regulatory taxes" are implausible on their own assumptions. Is it reasonable that regulations account for $91 \%$ of a housing lot price in Los Angeles and Detroit, and 88\% in San Francisco (Glaeser \& Gyourko, 2003, p.30)? Other studies have estimated similarly high regulatory taxes of $74 \%$ in Sydney, Australia, and 89\% in Auckland, New Zealand (Kendall \& Tulip, 2018; Lees, 2018).

Second, Murray (2020) applied the regulatory tax approach to land sales data from 1850s colonial Australia and from archaeological property sales records from ancient Mesopotamia. Even these places at these times had higher average than marginal housing lot prices, supporting the equilibrium value curve assumption that this pattern is a normal feature of all property markets, not an artefact of regulatory constraints.

\section{References}

Colwell, P. F., \& Sirmans, C. F. (1993). A comment on zoning, returns to scale, and the value of undeveloped land. The Review of Economics and Statistics, 783--786.

Glaeser, Edward L., \& Gyourko, Joseph. (2003). The Impact of Building Restrictions on Housing Affordability. Federal Reserve Bank of New York Policy Review, 9(2), $21-39$.

Kendall, Ross, \& Tulip, Peter. (2018). The Effect of Zoning on Housing Prices. Research Discussion Paper 2018-03. Reserve Bank of Australia.

Lees, Kirdan. (2018). Quantifying the costs of land use regulation: evidence from New Zealand. New Zealand Economic Papers, May, 1-25.

Murray, C. K. (2020). Marginal and average prices of land lots should not be equal: A critique of Glaeser and Gyourko's method for identifying residential price effects of town planning regulations. Environment and Planning A: Economy and Space, 0308518X20942874. 